\title{
The Clinical Status of Radiation Therapy in Korea in 2009 and 2013
}

\section{Jin-Kyu Kang, $M D^{1}$ \\ Mi-Sook Kim, MD, PhD ${ }^{1,2}$ \\ Won-II Jang, MD \\ Hee Jin Kim² \\ Chul Koo Cho, MD, PhD' \\ Hyung Jun Yoo, MD'1 \\ Young Seok Seo, MD ${ }^{1}$ \\ Eun Kyung Paik, MD \\ Yu Jin Cha, $\mathrm{MD}^{1}$}

\begin{abstract}
Purpose
The purpose of this study is to estimate the clinical status of radiation therapy (RT) in Korea.

Materials and Methods

We analyzed open claims data from the Health Insurance Review and Assessment Service (HIRA). The subjects were patients with malignant neoplasms who had procedure codes concerning RT in 2009 and 2013.
\end{abstract}

\section{Results}

The total numbers of patients who underwent RT in 2009 and 2013 were 42,483 and 56,850 , respectively. The numbers of men and women were 20,012 and 22,471 in 2009 and 26,936 and 29,914 in 2013, respectively. The five most frequent RT sites were metastatic, breast, gastrointestinal, thoracic, and gynecologic cancers in 2009, and metastatic, breast, gastrointestinal, thoracic and head and neck cancers in 2013. The three leading types of cancer among men were metastatic, gastrointestinal, and thoracic, and breast, metastatic, and gynecologic among women. According to age, the most common treatment site was the central nervous system for those aged 20 years or less, the breast for those in their 30s to 50s, and metastatic sites for those in their 60s or older.

\section{Conclusion}

Data from this study provide an overview of the clinical status of RT in Korea.

Correspondence: Mi-Sook Kim, MD, PhD

Department of Radiation Oncology,

Korea Institute of Radiological and

Medical Sciences, 75 Nowon-ro, Nowon-gu,

Seoul 01812, Korea

Tel: 82-2-970-2484

Fax: 82-2-970-2412

E-mail: mskim@kirams.re.kr

Received October 1, 2015

Accepted November 24, 2015

Published Online December 14, 2015

\author{
Key words \\ Neoplasms, Radiotherapy, Statistics, Korea, 2009, 2013
}

\section{Introduction}

As in many other parts of the world, cancer is the leading cause of death and is a major public health problem in Korea. According to the annual report of the Korea Central Cancer Registry, 224,177 patients were newly diagnosed with cancer in 2012, and overall incidence rates have increased by $3 \%-4 \%$ per year [1]. The number of individuals diagnosed with cancer has increased each year, due in large part to aging and particularly for some cancers (e.g., breast and colorectal cancer) because of the increasing prevalence of obesity attributed to westernized eating habits, and for some other cancers (e.g., thyroid and prostate cancer) because of the development of diagnostic tools and as a result of a medical system that encourages cancer screening [2].

In addition to surgery and chemotherapy, radiation therapy (RT) is one of the three primary modalities for modern cancer treatment. As the market and clinical demand for RT grow in importance, providing accurate, nationally based 
Table 1. The customized source population

\begin{tabular}{|c|c|}
\hline List & Criterion \\
\hline Treatment period & $\begin{array}{l}2009 \text { Jan 1-2009 Dec 31, } \\
2013 \text { Jan 1-2013 Dec } 31\end{array}$ \\
\hline Type of healthcare facility & Tertiary, secondary \\
\hline Diagnostic code & C00-C97 \\
\hline Type of insurance & Health insurance, medical aid \\
\hline Hospital region & National \\
\hline Sex & Male, female \\
\hline Age & All ages \\
\hline
\end{tabular}

databases concerning the clinical status of RT has become important for understanding the status and development of cancer treatment in Korea. Official records concerning the clinical status of RT were reported from 1999 to 2006 in Korea [3-6]. The results were compiled from questionnaires mailed to radiation oncology facilities. A website with relevant RT statistics from the Korean Society for Radiation Oncology (KOSRO) was recently developed and is being operated as an on-line statistical program [7]; these developments may be helpful for taking inventory of the RT equipment and for evaluating the manpower status for radiation oncology in Korea. However, these approaches require a long period of time as well as the cooperation of all RT facilities for data collection.

In this study, we analyzed the clinical status of RT in 2009 and 2013 in Korea using open claims data from the Health Insurance Review and Assessment Service (HIRA).

\section{Materials and Methods}

The claims data from the HIRA are open access to approved researchers who submit a profile of their work and R\&D plan. The claims data from the HIRA contain information on 46 million patients per year who account for $90 \%$ of the total population in Korea; the claims data include information regarding patients' diagnoses, treatment, procedures,

Table 2. Procedure codes related to radiation therapy

\begin{tabular}{|c|c|}
\hline HD051 & Teletherapy-Low energy-Single port \\
\hline HD052 & Teletherapy-Middle energy-Single port \\
\hline HD053 & Teletherapy-High energy-Single port \\
\hline HD054 & Teletherapy-Low energy-Paralleled opposed ports \\
\hline HD055 & Teletherapy-Middle energy-Paralleled opposed ports \\
\hline HD056 & Teletherapy-High energy-Paralleled opposed ports \\
\hline HD058 & Rotational irradiation- Middle energy radiation therapy \\
\hline HD059 & Rotational irradiation - High energy radiation therapy \\
\hline HD061 & 3-Dimensional conformal therapy \\
\hline HD080 & External radioisotope therapy \\
\hline HD081-HD082 & Intracavitary therapy-High dose rate \\
\hline HD083-HD084 & Intracavitary therapy-Low dose rate \\
\hline HD085-HD086 & Interstitial, intraluminal therapy-High dose rate \\
\hline HD088 & Interstitial, intraluminal therapy-Low dose rate \\
\hline HD089 & Brachytherapy \\
\hline HD091 & Total body irradiation \\
\hline HD092 & Total body lymph node irradiation \\
\hline HD093 & Total skin electron beam therapy \\
\hline HD110 & Fractionated stereotactic radiotherapy \\
\hline HD111-HD112 & Body stereotactic radiosurgery-Using linear accelerator \\
\hline HD113 & Cranial stereotactic radiosurgery-Gamma knife \\
\hline HD114 & Cranial stereotactic radiosurgery-Cyber knife \\
\hline HD115 & Cranial stereotactic radiosurgery-Linear accelerator \\
\hline HD121 & Proton therapy \\
\hline HD211-HD212 & Stereotactic body radiosurgery-Using cyber knife \\
\hline HZ271 & Intensity modulated radiation therapy \\
\hline
\end{tabular}




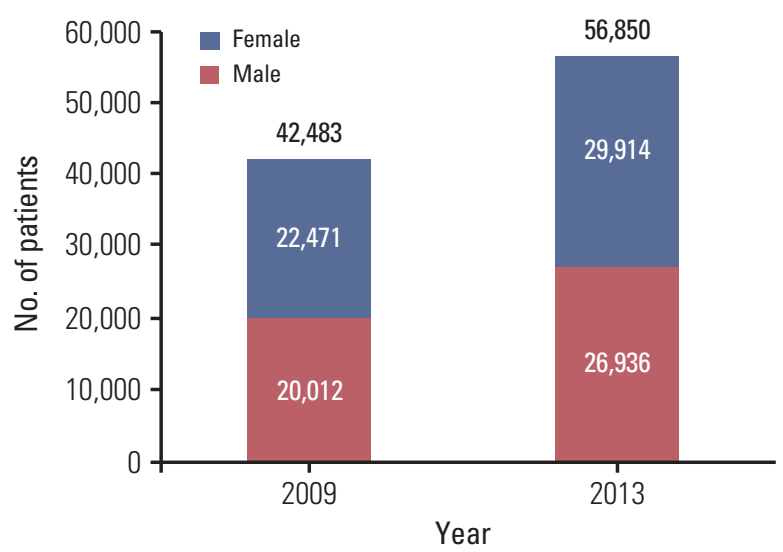

Fig. 1. Total number of patients who underwent radiation therapy in 2009 and 2013 in Korea.

surgical history, and prescription drugs, which provide a valuable resource for healthcare research [8].

The customized source population criteria for this study are shown in Table 1. The source population consisted of all patients who had any of the International Classification of Diseases 10 (ICD-10) cancer diagnoses (C00-C97) and at least one of the procedure codes related to receiving RT (Table 2) from January to December in 2009 and 2013. Patients who received two or more sessions of RT with interruption through January to December were counted as one patient. Patients with a diagnostic code concerning metastases (C7779) were categorized as having received RT to a metastatic site. Patients with two or more diagnostic codes related to malignant neoplasms were categorized as having received RT to the metastatic site, followed by the main, secondary, and third diagnostic codes.

The site of RT category classification was based on the annual reports from the KOSRO, except for the breast and thyroid, which were classified independently rather than as part of the thoracic category.

\section{Results}

The total numbers of patients who underwent RT in 2009 and 2013 were 42,483 and 56,850, respectively. The total numbers of male and female patients who received RT were 20,012 and 22,471 in 2009, 26,936 and 29,914 in 2013, respectively (Fig. 1). The numbers of patient who received RT in 2009 and 2013 by cancer sites and sex are shown in Table 3 . The five most frequent sites for patients who underwent RT in 2009 were as follows: metastatic (brain, bone, lymph node, and others), breast, gastrointestinal, thoracic, and gynecologic. However, the fifth most frequent site in 2013 was head and neck cancer instead of gynecologic cancer. The three leading sites among male patients were metastatic, gastrointestinal, and thoracic cancer, and breast, metastatic, and gynecologic cancer among women, in that order. The numbers of patients who received RT according to site and age group in 2013 are shown in Table 4. The most common treatment site was the central nervous system for those in their 20 s or younger, while the breast was the most frequent site through the 30s to 50s, and metastasis was most common for those in their 60s or older. Similar trends were observed in 2009.

\section{Discussion}

This study was conducted to analyze the clinical status of RT in 2009 and 2013 in Korea using claims data from the HIRA. Using the annual reports of KOSRO, we determined that the total number of patients who received RT increased by $33 \%$ every 4 years (Fig. 2). Although the absolute number of patients who received RT has been increasing steadily, because the cancer incidence has also increased steadily over the same period [9-12], the percentages of cancer patients who underwent irradiation were expected to be consistently below 30\% over the period from 1999 to 2013.

Breast, gastrointestinal, and genitourinary cancers have shown the steepest increase in number and proportion (Fig. 3). This tendency could be explained not only by the increasing cancer incidence, but also by the increasing evidence supporting the use of RT through well-designed studies and with the advancement of RT techniques.

This approach, using claims data from the HIRA, could reduce the amount of time required to obtain data from participants from each RT facility and eliminate the possible recall bias associated with questionnaire-based studies. In addition, claims data from the HIRA can be analyzed easily by age group, as shown in Table 4 .

However, this study had several limitations. Because the claims data from the HIRA only include the insured cases, uninsured treatments, such as intensity modulated RT, cannot be analyzed. In addition, we included patients with the ' $\mathrm{C}$ ' code and excluded benign disease. Therefore, patients who had a ' $\mathrm{D}$ ' diagnostic code, which is expected to be a somewhat large portion of patients with ductal carcinoma in situ of the breast treated by RT, were excluded from this analysis. As a result, the actual number of patients who received RT is expected to be more than what is reported. To the contrary, because the patients who received RT on mul- 
Table 3. Distribution of patients who received radiation therapy according to tumor site and sex in 2009 and 2013

\begin{tabular}{|c|c|c|c|c|c|c|c|}
\hline \multirow{2}{*}{ Site } & \multirow{2}{*}{ Sub-site (diagnostic code) } & \multicolumn{3}{|c|}{ No. of patients in 2009} & \multicolumn{3}{|c|}{ No. of patients in 2013} \\
\hline & & Male & Female & Total & Male & Female & Total \\
\hline Metastasis & $(\mathrm{C} 77-\mathrm{C} 79)$ & 7,435 & 6,280 & 13,715 & 8,529 & 6,894 & 15,423 \\
\hline Breast & $(\mathrm{C} 50)$ & 11 & 8,731 & 8,742 & 17 & 13,480 & 13,497 \\
\hline \multirow[t]{9}{*}{ Gastrointestinal } & Colorectum (C18-C20) & 2,129 & 1,109 & 3,238 & 2,416 & 1,203 & 3,619 \\
\hline & Hepatobiliary (C22-C24) & 1,706 & 566 & 2,272 & 2,329 & 746 & 3,075 \\
\hline & Esophagus (C15) & 737 & 43 & 780 & 992 & 79 & 1,071 \\
\hline & Pancreas (C25) & 226 & 147 & 373 & 397 & 275 & 672 \\
\hline & Stomach (C16) & 232 & 108 & 340 & 290 & 133 & 423 \\
\hline & Anus (C21) & 49 & 72 & 121 & 62 & 109 & 171 \\
\hline & Small bowel (C17) & 13 & 5 & 18 & 17 & 12 & 29 \\
\hline & Other (C26) & 2 & 0 & 2 & 1 & 0 & 1 \\
\hline & Subtotal & 5,094 & 2,050 & 7,144 & 6,504 & 2,557 & 9,061 \\
\hline \multirow[t]{6}{*}{ Thoracic } & Lung (C34) & 2,576 & 551 & 3,127 & 4,073 & 1,045 & 5,118 \\
\hline & Thymus (C37) & 86 & 70 & 156 & 115 & 80 & 195 \\
\hline & Mediastinum (C38) & 20 & 4 & 24 & 31 & 7 & 38 \\
\hline & Trachea (C33) & 6 & 7 & 13 & 6 & 8 & 14 \\
\hline & Other (C39) & 1 & 0 & 1 & 1 & 0 & 1 \\
\hline & Subtotal & 2,689 & 632 & 3,321 & 4,226 & 1,140 & 5,366 \\
\hline \multirow[t]{12}{*}{ Head and neck } & Larynx (C32) & 575 & 32 & 607 & 832 & 36 & 868 \\
\hline & Oral cavity $(\mathrm{C} 02-\mathrm{C} 06)$ & 183 & 89 & 272 & 304 & 178 & 482 \\
\hline & Oropharynx (C01, C09-C10) & 193 & 35 & 228 & 395 & 66 & 461 \\
\hline & Nasopharynx (C11) & 125 & 42 & 167 & 271 & 92 & 363 \\
\hline & Salivary gland (C07-C08) & 127 & 77 & 204 & 163 & 116 & 279 \\
\hline & Hypopharynx (C12-C13) & 181 & 14 & 195 & 248 & 17 & 265 \\
\hline & Paranasal sinus (C31) & 57 & 27 & 84 & 82 & 39 & 121 \\
\hline & Nasal cavity (C30) & 48 & 19 & 67 & 64 & 34 & 98 \\
\hline & Eye and orbit (C69) & 17 & 16 & 33 & 23 & 16 & 39 \\
\hline & $\operatorname{Lip}(C 00)$ & 8 & 2 & 10 & 5 & 5 & 10 \\
\hline & Other (C14) & 4 & 1 & 5 & 15 & 0 & 15 \\
\hline & Subtotal & 1,518 & 354 & 1,872 & 2,402 & 599 & 3,001 \\
\hline \multirow[t]{6}{*}{ Gynecologic } & Uterine cervix (C53) & - & 1,942 & 1,942 & - & 2,095 & 2,095 \\
\hline & Uterine corpus (C54-C55) & - & 521 & 521 & - & 618 & 618 \\
\hline & Ovary and tubes (C56) & - & 72 & 72 & - & 111 & 111 \\
\hline & Vagina and vulva (C51-C52) & - & 87 & 87 & - & 84 & 84 \\
\hline & Other (C57-C58) & - & 3 & 3 & - & 5 & 5 \\
\hline & Subtotal & - & 2,625 & 2,625 & - & 2,913 & 2,913 \\
\hline \multirow[t]{6}{*}{ Genitourinary } & Prostate (C61) & 847 & - & 847 & 2,097 & - & 2,097 \\
\hline & Ureter and bladder (C66-C67) & 178 & 52 & 230 & 291 & 69 & 360 \\
\hline & Kidney (C64-C65) & 47 & 17 & 64 & 77 & 38 & 115 \\
\hline & Penis and testis (C60, C62-C63) & 34 & - & 34 & 53 & - & 53 \\
\hline & Other (C68) & 0 & 4 & 4 & 0 & 7 & 7 \\
\hline & Subtotal & 1,106 & 73 & 1,179 & 2,518 & 114 & 2,632 \\
\hline \multirow[t]{4}{*}{ Central nervous system } & Brain (C70-C71) & 700 & 557 & 1,257 & 815 & 656 & 1,471 \\
\hline & Spinal cord (C72) & 20 & 12 & 32 & 17 & 24 & 41 \\
\hline & Other (C47) & 11 & 7 & 18 & 23 & 18 & 41 \\
\hline & Subtotal & 731 & 576 & 1,307 & 855 & 698 & 1,553 \\
\hline \multirow[t]{4}{*}{ Lymphoma } & Hodgkin's disease (C81) & 58 & 23 & 81 & 61 & 26 & 87 \\
\hline & Non-Hodgkin's lymphoma (C82-C88) & 541 & 398 & 939 & 676 & 542 & 1,218 \\
\hline & Other (C96) & 2 & 2 & 4 & 9 & 7 & 16 \\
\hline & Subtotal & 601 & 423 & 1,024 & 746 & 575 & 1,321 \\
\hline
\end{tabular}


Table 3. Continued

\begin{tabular}{|c|c|c|c|c|c|c|c|}
\hline \multirow{2}{*}{ Site } & \multirow{2}{*}{ Sub-site (diagnostic code) } & \multicolumn{3}{|c|}{ No. of patients in 2009} & \multicolumn{3}{|c|}{ No. of patients in 2013} \\
\hline & & Male & Female & Total & Male & Female & Total \\
\hline Soft tissue & $(\mathrm{C} 46, \mathrm{C} 49)$ & 177 & 140 & 317 & 295 & 219 & 514 \\
\hline Myeloma and plasmacytoma & $(\mathrm{C} 90)$ & 132 & 125 & 257 & 179 & 163 & 342 \\
\hline Leukemia & (C91-C95) & 159 & 115 & 274 & 170 & 132 & 302 \\
\hline Skin & $(\mathrm{C} 44)$ & 84 & 83 & 167 & 123 & 102 & 225 \\
\hline Thyroid & $(\mathrm{C} 73)$ & 57 & 122 & 179 & 72 & 134 & 206 \\
\hline Malignant melanoma & $(\mathrm{C} 43)$ & 38 & 34 & 72 & 68 & 61 & 129 \\
\hline Primary bone and cartilage & (C40-C41) & 69 & 42 & 111 & 59 & 38 & 97 \\
\hline Endocrine & $(\mathrm{C} 74-\mathrm{C} 75)$ & 26 & 14 & 40 & 37 & 22 & 59 \\
\hline Others & (C45, C48, C76, C80, C97) & 85 & 52 & 137 & 136 & 73 & 209 \\
\hline Total & & 20,012 & 22,471 & 42,483 & 26,936 & 29,914 & 56,850 \\
\hline
\end{tabular}

Table 4. The number of patients who received radiation therapy by site and age group in 2013

\begin{tabular}{|c|c|c|c|c|c|c|c|}
\hline \multirow{2}{*}{ Treatment site } & \multicolumn{6}{|c|}{ Age group } & \multirow{2}{*}{ Total } \\
\hline & 20 s or under & $30 \mathrm{~s}$ & $40 \mathrm{~s}$ & $50 \mathrm{~s}$ & $60 \mathrm{~s}$ & 70 s or older & \\
\hline Metastasis & 150 & 614 & 2,150 & 4,351 & 4,240 & 3,918 & 15,423 \\
\hline Breast & 137 & 1,411 & 4,976 & 4,412 & 1,872 & 689 & 13,497 \\
\hline Gastrointestinal & 15 & 178 & 880 & 2,605 & 2,753 & 2,630 & 9,061 \\
\hline Respiratory & 18 & 60 & 300 & 989 & 1,774 & 2,225 & 5,366 \\
\hline Head and neck & 54 & 132 & 343 & 816 & 867 & 789 & 3,001 \\
\hline Gynecologic & 45 & 257 & 611 & 911 & 529 & 560 & 2,913 \\
\hline Genitourinary & 13 & 20 & 58 & 289 & 854 & 1,398 & 2,632 \\
\hline Central nervous system & 227 & 159 & 285 & 343 & 300 & 239 & 1,553 \\
\hline Lymphoma & 126 & 127 & 215 & 333 & 243 & 277 & 1,321 \\
\hline Soft tissue & 61 & 53 & 75 & 99 & 105 & 125 & 518 \\
\hline Myeloma and plasmacytoma & 0 & 8 & 34 & 87 & 118 & 95 & 342 \\
\hline Leukemia & 118 & 66 & 47 & 45 & 23 & 3 & 302 \\
\hline Skin & 3 & 11 & 25 & 32 & 42 & 112 & 225 \\
\hline Thyroid & 7 & 10 & 26 & 60 & 42 & 61 & 206 \\
\hline Malignant melanoma & 0 & 8 & 17 & 36 & 37 & 31 & 129 \\
\hline Primary bone and cartilage & 25 & 5 & 12 & 26 & 16 & 13 & 97 \\
\hline Endocrine & 18 & 5 & 10 & 8 & 10 & 8 & 59 \\
\hline Others & 9 & 6 & 24 & 51 & 53 & 62 & 205 \\
\hline All cancer & 1,026 & 3,130 & 10,088 & 15,493 & 13,878 & 13,235 & 56,850 \\
\hline
\end{tabular}

tiple sites including primary or metastatic sites throughout the treated years could be re-counted as annual new patients, the actual total number of patients who received RT is expected to be less than what we reported. Therefore, the annual number of patients who received RT should be considered under these limitations. In addition, the 'metastasis' category, which accounts for the largest proportion of patients in this study, may reduce the number of patients who received RT to each primary cancer site. Because we cannot distinguish whether the patients actually received RT to a metastatic site or to a primary site in cases with a metastatic diagnostic code, we assumed that the patients with metastatic diagnostic codes received RT to a metastatic site. As a result, the proportions of patients who received RT to metastatic sites were high in this study. According to the RT statistics data published in KOSRO, the portion of the 'metastasis' category for all patients receiving RT was 15\%18\% between 1999 and 2006 [3-6]; however, the proportions of the 'metastasis' category were 32\% in 2009 and $27 \%$ in 2013 in the current study. This may have been an under-estimation of the number of each primary cancer site. 


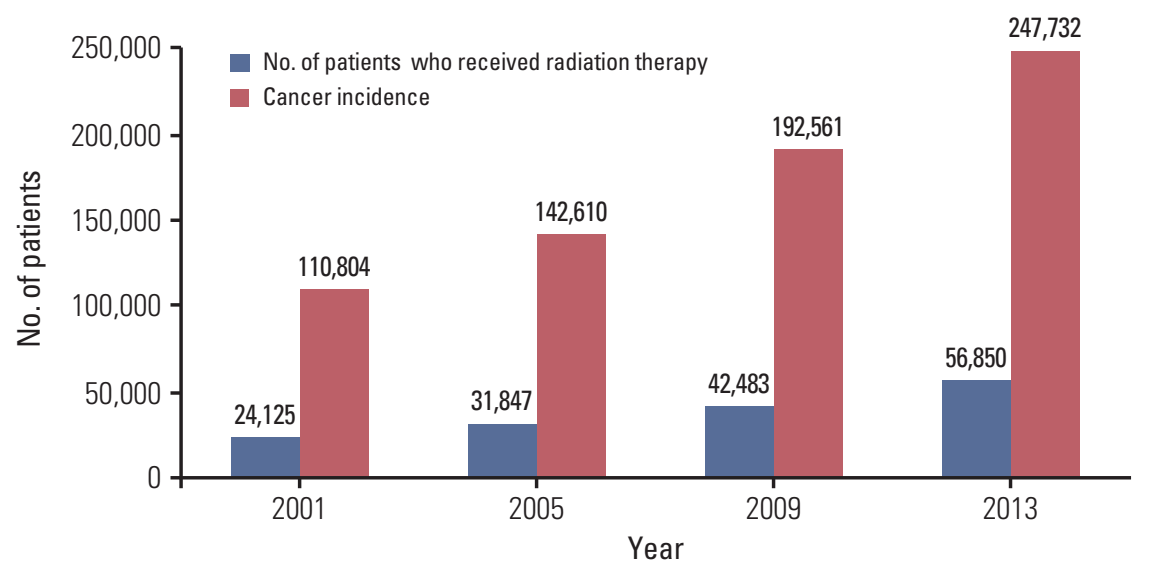

Fig. 2. Cancer incidence and total number of patients who received radiation therapy through 2001 to 2013 in Korea. The cancer incidence for 2013 is the value predicted by Jung et al. [12].

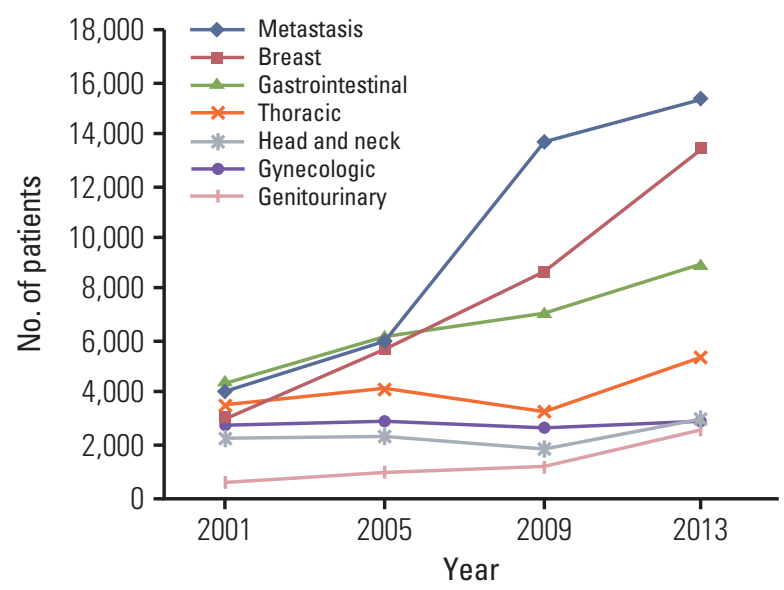

Fig. 3. Time course of the number of patients who received radiation therapy at seven main sites.

\section{Conclusion}

In conclusion, the number of patients who received RT in Korea has shown a steady increase; however, the percentages of cancer patients who underwent irradiation were expected to still be below $30 \%$. Although the use of claims data from the HIRA has some limitations, it provided useful cumulative clinical data supporting RT as one of the main modalities for cancer treatment in Korea.

\section{Conflicts of Interest}

Conflict of interest relevant to this article was not reported.

\section{Acknowledgments}

This work was supported by the National Nuclear R \& D program of the Ministry of Education, Science and Technology, Republic of Korea. 


\section{References}

1. Jung KW, Won YJ, Kong HJ, Oh CM, Cho H, Lee DH, et al. Cancer statistics in Korea: incidence, mortality, survival, and prevalence in 2012. Cancer Res Treat. 2015;47:127-41.

2. Lee TJ, Kim S, Cho HJ, Lee JH. The incidence of thyroid cancer is affected by the characteristics of a healthcare system. J Korean Med Sci. 2012;27:1491-8.

3. You SY, Kim MS, Ji YH, Cho CK, Yang KM, Ryu HJ. National statistics of radiation oncology in Korea (1999-2001). J Korean Soc Ther Radiol Oncol. 2004;22:234-6.

4. Kim MS, Ji YH, You SY, Cho CK, Yang KM, Ryu HJ. National statistics of radiation oncology in Korea (2002-2004). J Korean Soc Ther Radiol Oncol. 2006;24:77-80.

5. Kim MS, Ji YH, You SY, Cho CK, Yang KM, Ryu HJ, et al. National statistics of radiation oncology in Korea (2005). J Korean Soc Ther Radiol Oncol. 2006;24:207-9.

6. Ji YH, Kim MS, You SY, You DH, Choi MS, Jung HJ. National statistics of radiation oncology in Korea (2006). J Korean Soc Ther Radiol Oncol. 2008;26:131-3.
7. Song SY, Ahn SD, Chung WK, Shin KH, Choi EK, Cho KH. Development of new on-line statistical program for the Korean Society for Radiation Oncology. Radiat Oncol J. 2015;33:142-8.

8. Kim L, Kim JA, Kim S. A guide for the utilization of Health Insurance Review and Assessment Service National Patient Samples. Epidemiol Health. 2014;36:e2014008.

9. Ji YH, Kim MS, Jung H, Yoo SY, Cho CK. Clinical characteristics of radiation oncology in Korea during past 10 years. J Korean Med Sci. 2009;24:1165-9.

10. Jung KW, Won YJ, Park S, Kong HJ, Sung J, Shin HR, et al. Cancer statistics in Korea: incidence, mortality and survival in 2005. J Korean Med Sci. 2009;24:995-1003.

11. Jung KW, Park S, Kong HJ, Won YJ, Lee JY, Seo HG, et al. Cancer statistics in Korea: incidence, mortality, survival, and prevalence in 2009. Cancer Res Treat. 2012;44:11-24.

12. Jung KW, Won YJ, Kong HJ, Oh CM, Seo HG, Lee JS. Prediction of cancer incidence and mortality in Korea, 2013. Cancer Res Treat. 2013;45:15-21. 